\title{
Mark D. Lee, Entretien avec Amélie Nothomb
}

\section{Katia Cassano}

\section{(2) OpenEdition}

\section{Journals}

\section{Edizione digitale}

URL: http://journals.openedition.org/studifrancesi/33732

DOI: 10.4000/studifrancesi.33732

ISSN: 2421-5856

\section{Editore}

Rosenberg \& Sellier

\section{Edizione cartacea}

Data di pubblicazione: 1 décembre 2005

Paginazione: 680

ISSN: 0039-2944

\section{Notizia bibliografica digitale}

Katia Cassano, «Mark D. Lee, Entretien avec Amélie Nothomb», Studi Francesi [Online], 147 (XLX | III) | 2005, online dal 30 novembre 2015, consultato il 20 avril 2021. URL: http://journals.openedition.org/ studifrancesi/33732 ; DOI: https://doi.org/10.4000/studifrancesi.33732

\section{Questo documento è stato generato automaticamente il 20 avril 2021.}

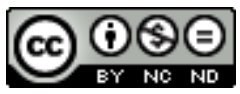

Studi Francesi è distribuita con Licenza Creative Commons Attribuzione - Non commerciale - Non opere derivate 4.0 Internazionale. 


\title{
Mark D. Lee, Entretien avec Amélie Nothomb
}

\author{
Katia Cassano
}

\section{NOTIZIA}

MARK D. LEE, Entretien avec Amélie Nothomb, “The French Review”, 3, 77, 2004, pp. 562-575.

1 In questa intervista del febbraio 2002, si mette l'accento sulle origini, l'evoluzione e la ricezione dell'opera della scrittrice, esplorando al contempo i legami tra realtà e finzione nei suoi romanzi.

2 Argomento principale, fondamentale per comprendere appieno l'opera nothombiana, è il rapporto tra lo scrivere e il mangiare. Amélie Nothomb ha incominciato a scrivere a diciassette anni, dopo due anni e mezzo di anoressia. Forse il desiderio della scrittura è sempre stato insito in lei ma, solo in seguito alla malattia, ha preso forma materialmente, la scrittrice infatti pensa che senza la malattia non avrebbe mai iniziato a scrivere; inoltre molti suoi personaggi sono obesi e provocano in lei una sorta di repulsione, perché rappresentano il male, male - in senso assoluto, ma anche come dolore fisico- che ha provato quando ha ricominciato a mangiare. Il rapporto negativo con il cibo ha continuato ad influenzare la sua vita durante parecchi anni: non accettando il suo corpo ella non si sentiva accettata dagli altri.

3 Molto prolifica, Amélie Nothomb racconta la sua scrittura e fornisce al lettore particolari personali circa questa pratica, illustrando l'origine dei suoi libri e il rapporto quasi viscerale che la lega alle sue "creature".

4 Tra le caratteristiche principali dei romanzi di Amélie Nothomb, che sono qui evidenziate, si rileva la presenza dei dialoghi che nascono direttamente nella sua mente, ma le diverse voci sono talmente chiare che è impossibile confondersi. 
5 Per concludere Amélie Nothomb dichiara di considerarsi uno scrittore francofono, l'etichetta di scrittrice le sembra alquanto riduttiva e inoltre, data la sua infanzia cosmopolita, sente di non appartenere a nessuna nazione in particolare. 